\title{
REVIEW:APPLICATION OF BIG DATA AND IOT PROTECTED MODE IN AGRICULTURE
}

\author{
Dr.Anita K.Patil \\ Department of Electronics \& Telecommunication \\ DVVPCOE, Ahmednagar, Maharashtra, India
}

\begin{abstract}
Advance researches in the field of Internet of Things (IoT) are helping to make water management smarter and also used for optimizing consumption in the smart agriculture industry. Now days the development and research in Intelligent Smart Farming IoT based devices is turning the face of agriculture production in enhancing as well making it cost-effective and reducing wastage. To create environmental conditions suitable for the growth of animals and plants, modern agriculture that uses artificial techniques to change climatic factors such as temperature a highly efficient protected agriculture mode is used. To handle the increasing challenges of agricultural production, the complex agricultural ecosystems need to be better understood. Modern digital technology used for continuously monitoring the physical environment and producing large quantities of data in an unprecedented pace. For improving productivity the analysis of big data would enable farmers and companies to extract value from it. Moreover big data analysis is leading to advances in various industries; it has not yet been widely applied in agriculture. The objective of this paper is to perform a review on current studies and research works in agriculture which employs the recent practice of big data analysis, in order to solve various relevant problems.
\end{abstract}

Keywords - Agriculture, Big Data, Cloud computing, Data communication, IoT (Internet of Things), Protected mode, Smart farming

\section{INTRODUCTION}

Agricultural production demands lot of activities such as soil and plant monitoring, environmental monitoring (moisture and temperature), transportation, control systems management, supply chain management, infrastructure management, animal monitoring, pest control etc. Smart farming is important due to the challenges of agricultural production related to productivity, environmental impact, food security and sustainability.

The aforementioned emerging digital technologies contribute with data generated from GPS and Smart Sensors on agricultural field and integration of smart farming equipment along with Big Data analytics. Farmers would be able to improve crop yields and make effective use of water and wastage of any sort would be reduced to a remarkable level.

\author{
Dr.A.R.Laware \\ Department of Electrical \\ DVVPCOE, Ahmednagar, Maharashtra, India
}

The objective of this research paper is to propose IoT Based Smart Stick which will enable farmers to have live data of soil moisture, environment temperature at very low cost so that live monitoring can be done.

\section{AgRiculture RElATED WORK}

Vietnam is a farming country that is becoming rapidly enjoying benefit of basic characteristic assets. Horticulture assumes a fundamental part in the Vietnamese economy and adds to the country's monetary improvement as of now and later on. Financial development relies intensely upon agribusiness mechanical areas of Vietnam.

In 2020 the number of inhabitants in Vietnam will ascend to contact 100 million individuals, while the interest for agrarian items, for example, food crops yams, manioc, beans, and corn also rice, cashew nut, espresso, pepper, , elastic, tea, natural product, and vegetables drastically keeps on expanding. Joined with the impacts of environmental change, these requests place much more strain upon land, water, energy, and different assets that are as of now affected. Due to moving force and water assets productively, a few shrewd arrangements can be co-advanced and increased to improve yields and meet developing food creation demands [17]. Numerous articles portray the cozy connection between shrewd farming and Internet of Things/Wireless Sensor organization. Cutting edge improvement can be utilized by scientists to foster viable brilliant frameworks and information transmission.

The creators of [18] present a Smart Farm Net structure, in view of the IoT stage that can robotize the assortment of ecological, compost, soil, and water system information; consequently correspond that information and assess item execution; and compute item appraises and propose explicit items for a specific homestead. Web of Things gadgets can be coordinated into this stage as climate stations, cameras and sensors. Created information would then be able to be saved in the cloud to empower execution investigation and proposals. Undeniable level correspondence innovation, for example, IEEE 802.15.4 utilized for man-made reasoning, and choice help innovation, the creators of [12] have created research strategy in agrarian use of IoT innovation to constant observing continuous dampness and supplements of citrus, also an examination of the blend of manure emotionally supportive networks and water system. Notwithstanding, this 


\section{International Journal of Engineering Applied Sciences and Technology, 2021 \\ Vol. 5, Issue 12, ISSN No. 2455-2143, Pages 63-68 \\ Published Online April 2021 in IJEAST (http://www.ijeast.com)}

examination has shortcomings, which incorporate framework intricacy and significant expenses.

The creators of [9] portray a restricted band radio channel model and present the correspondence connect moves under close ground prerequisites for a brilliant horticulture stage for ranchers. In this sensors can be applied for use in the IoT framework. Besides, $2 \mathrm{G}$ and $3 \mathrm{G}$ remote broadband organizations can be utilized for correspondence between different segments in the IoT system. Several empowering advancements are adjusted to introduce shrewd stage projects, which can gather and oversee information taking care of issues identified with water the board in savvy agriculture. For model, the SWAMP project is a stage engineering that incorporates a situation based improvement measure for the acquired frameworks in [2]. Also, the stage creates and surveys brilliant water the board for exactness water system in farming with a commonsense strategy dependent on four pilots in Brazil, Italy, and Spain. The design of SWAMP can be created for various answers for manage the prerequisites of various settings, nations, environments, soils, and harvests. In reality, significant adaptability is needed to adjust to a scope of organization setups, including a different blend of innovations. Tragically, for this stage, it is absurd to expect to use without the license. To deal with the assortment, examination, and figure of agrarian ecological data in one widespread framework cloud-based innovation is utilized and diverse IoT brilliant stages introduced in [5]. The creator of the paper likewise introduced LoRa correspondence and applied it to the contemplated network. In outline, the two investigations introduced intriguing ideas and appropriate stages for application to keen horticulture. A few creators have zeroed in on finishing a precise writing survey examination of Internet of Things and recent years organizations in ensured farming. In like manner, they assess the commitments made by different analysts and associations

Additionally, the construction of IoT is likewise point by point in ensured horticulture, including the pre-owned stages, present day remote advances, distributed computing, AI, large information, animal cultivating, equipment, programming difficulties, etc. Another paper [7] proposes an IoT thought based answer for shrewd cultivating, where the creators proposed stack and examine the current upgrades. Analysts for the most part center around the Internet of things and machine to machine connection additionally clarify the plan and advancement of an entryway and offered types of assistance. Outstandingly, in [4], the Web of Things (WoT) was proposed as a plan to utilize ecological checking and improve horticultural practices by supporting dynamic dependent on bio-information assortment. This paper, presents the first plan, for example, middleware stage for IoT which performs detachment by processing activities and comprehension entrepreneurial systems administration. In [3], electromagnetic field investigation is introduced as an improved observing methodology for subsurface radio wave spread and underground detecting applications in the field of forecast farming. To carry out in complex genuine conditions, such kind of innovation is testing. The forecast of the farming model introduced by [14] offers arrangement the board abilities by checking soil conditions continuously utilizing underground remote sensors. For the investigations, two sorts of correspondence joins, over the ground and underground design was utilized. Numerous well known frameworks and stages can be utilized for water the executives in keen agribusiness, yet might be excessively costly for the normal rancher [12-16]. The mix of numerous advancements in a single framework and the presence of constraints prompts intricacy when consolidating restrictive innovations. Numerous variables, for example, equipment configuration, managing documentation, and homestead influence the cost. Practically all Internet of things keen agribusiness arrangements available are inactive strategies (i.e., manual). To act sagaciously, now and then they are associated with ranch checking gadgets. For savvy agribusiness frameworks number of specialists depicts the arrangements. Be that as it may, these strategies are confined by the plan implanted board and the resoluteness of gadgets, as it very well might be important to append extra sensors or to control at least two ranches with a similar versatile application. Examination of proposed Internet of things based model with existing Literature.

Table 1

Advantages \& Disadvantages of WSN

\begin{tabular}{|c|l|l|}
\hline Model & \multicolumn{1}{|c|}{ Advantages } & \multicolumn{1}{c|}{ Disadvantages } \\
\hline Wireless & 1. Reduces cost & 1.Huge amount of data \\
Sensor & 2.Agriculture & will generate. \\
Network & productivity increases & 2. Requires challenging \\
& 3. Saves Energy & storage fir huge amount \\
& 4.Efficiency increases & of data. \\
& 5.Excellent & \\
& communication between & \\
& gateway and Farm & \\
& 6.Improves quality & \\
\hline
\end{tabular}

\section{ENABLING TECHNOLOGIES FOR IOT}

Spine of different empowering innovations, for example, Wireless Sensor Networks, Cloud Computing, Big Data, Embedded Systems, Security Protocols and Architectures, Protocols empowering correspondence, web administrations, Internet and Search Engines is Internet of Things. Enormous Data Analytics: Big information examination is the way toward analyzing huge informational collections containing different types of information types for example Large Data to uncover covered up designs, obscure relationships, market patterns, client inclinations and other valuable business data. Correspondence Protocols: They structure the foundation of IoT frameworks to empower availability and coupling to applications and these conventions work with trade of information over the organization as these conventions empower information trade designs, information encoding and 


\section{International Journal of Engineering Applied Sciences and Technology, 2021 \\ Vol. 5, Issue 12, ISSN No. 2455-2143, Pages 63-68 \\ Published Online April 2021 in IJEAST (http://www.ijeast.com)}

tending to. For information stockpiling and handling there is need for enormous interests in foundations because of huge information of horticulture. (Nandyala and Kim, 2016; Hashem et al., 2015), Weather guaging, checking for harvests, irritations and creatures' illnesses need to work progressively for certain applications. To depict another age of practices (Kempenaar et al., 2016; Sonka, 2016), major information investigation is utilized. Ranchers and related associations can separate monetary worth from enormous volumes of a wide assortment of information by empowering high-speed catch, revelation, and additionally examination (Waga and Rabah, 2014; Lokers et al., 2016).

\section{A. Big data Sources}

Considering the investigation performed, it merits inspecting the wellsprings of large information utilized by the various papers under examination, which start from different various sources, like the ranchers' field, for example from ground sensors (for example synthetic identification gadgets, biosensors, climate stations, and so forth) (Chedad et al., 2001; Kempenaar et al., 2016), (chronicled) information assembled by legislative and outsider associations (for example measurable yearbooks, administrative reports, guidelines and rules from public bodies, cautions, and so forth), conveyed through online archives and web administrations (McQueen et al., 1995; Tesfaye et al., 2016), information from airborne sensors (for example automated flying vehicles, planes and satellites) (Becker-Reshef et al., 2010; Gutiérrez et al., 2008), ongoing web information from privately owned businesses through online web administrations (GSMA, 2014; Syngenta, 2010), publicly supporting based procedures from cell phones like transportation information, data about plants, crops, yields, climate conditions, and so on (Akinboro, 2016; Global Envision, 2006), takes care of from online media a few models are g. referencing of normal perils occurring, bugs or

sicknesses distinguished in different ranches and fields (Sawant et al., 2016), and so on

\section{B. Agriculture: Benefits of IoT}

1. Assortment and the executives of huge loads of information gathered from sensors and with incorporation of distributed computing administrations like Agriculture fields maps, distributed storage and so on effectively empower by Internet of Things. Likewise information can be gotten to live from anyplace and all over the place and empowering live checking with start to finish network among every one of the concerned gatherings.

2. IoT is viewed as key segment for Smart Farming similarly as with precise sensors and brilliant equipment's, ranchers can expand the food creation by $70 \%$ till year 2050 as portrayed by specialists.
3. With IoT creations expenses can be decreased to a surprisingly which will thusly build productivity and supportability.

4. With IoT, effectiveness level would be expanded as far as use of Soil, Water, Fertilizers, and Pesticides and so on

5. Insurance of climate through different components done by Internet of Things.

\section{SOURCES AND TECHNIQUES FOR BIG DATA ANALYSIS PER AGRICULTURAL AREA}

1.Weather stations, studies, static recorded data (climate and environment information, earth perception information), distant detecting (satellites), geospatial information Machine learning (adaptable vector machines), factual examination, displaying, cloud stages, Map Reduce investigation, GIS geospatial investigation Tripathi et al. (2006), Fuchs and Wolff (2011), Schnase et al. (2014), and Tesfaye et al. (2016).

2. Recorded datasets like precipitation and temperature, land portrayal and yield phenology, rise, worldwide tree cover maps and so on Land Remote detecting for example satellites, engineered gap radar, planes. Geospatial information, camera sensors (multispectral imaging), climate stations Machine learning, for example, adaptable vector machines, NDVI vegetation files, Wavelet based sifting, picture handling, factual investigation, ghostly coordinating with procedures, reflectance and surface temperature computations Barrett et al. (2014), Schuster et al. (2011), Galford et al. (2008), Wardlow et al. (2007).

3. Creatures' exploration, verifiable data about soils and creatures (physiological attributes), ground sensors (nibbling movement, feed admission, weight, heat, milk creation of individual cows, sound), camera sensors (multispectral and optical) Machine learning (choice trees, neural organizations, versatile vector machines) McQueen et al. (1995), Kempenaar et al. (2016), Chedad et al. (2001), and Pierna et al. (2004).

4. AI, for example, adaptable vector machines, $\mathrm{K}$-implies grouping erc., Crops Ground sensors (metabolites), far off detecting (satellite), recorded datasets e.g.land use, public land data, factual information on yields. Wavelet based separating, Fourier change, NDVI vegetation records Urtubia et al. (2007), Waldhoff et al. (2012).

5. Soil Ground sensors (saltiness, electrical conductivity, dampness), cameras (optical), authentic information bases (for example AGRIC soils) Machine learning (K-implies grouping, plant-explicit information) Machine learning, calculated relapse), picture preparing, NDVI vegetation records Gutiérrez et al. (2008).

7. GIS geospatial information, factual information, measurable investigation, distant detecting, Machine picking up, demonstrating, reenactment, network-based examination, GIS geospatial investigation, picture handling Frelat et al. (2016), Jóźwiaka et al. (2016), Lucas and Chhajed (2004), and RIICE Partnership (2014) .Food accessibility and security Surveys, authentic data and information bases (for example CIALCA, ENAR, rice crop development datasets), 


\section{International Journal of Engineering Applied Sciences and Technology, 2021 \\ Vol. 5, Issue 12, ISSN No. 2455-2143, Pages 63-68 \\ Published Online April 2021 in IJEAST (http://www.ijeast.com)}

8. Biodiversity GIS geospatial information, authentic data and data sets (SER data set of untamed life species Statistics (Bayesian conviction organizations) Marcot et al. (2001).

9. Ranchers' dynamic Static authentic data and datasets (for example US government overview information), far off detecting (satellites, drones), climate stations, people as sensors, electronic information, enormous information stockpiling, message-situated middleware Sawant et al. (2016), and Field to Market (2015).

D. Farming: Big information

Chiet al. (2016) describe huge information as indicated by the accompanying five measurements:

- Volume (V1): The size of information gathered for investigation.

- Velocity (V2): The time window in which information is helpful and important. For instance, some information ought to be investigated in a sensible opportunity to accomplish a given assignment, models are creature sicknesses and to recognize bugs (PEAT UG, 2016) and (Chedad et al., 2001).

- Variety (V3): Multi-source (for example pictures, recordings, far off and field based detecting information), multi-transient (for example gathered on various dates/times), and multi-goal, for example, different spatial goal pictures and furthermore information having various organizations, from various sources and trains, and from a few application areas.

- Veracity (V4): Overall certainty including the quality, dependability and capability of the information, just as its precision and dependability.

- Valorization (V5): The capacity to spread information, appreciation and development.

\section{E. Big data : Applications in analysis of agriculture}

This examination covered the rural region concerned, the specific issue handled, the arrangement and additionally sway through the investigation performed, devices/calculations utilized for resolving the issue, wellsprings of information just as an assessment of the initial three "V"s of large information (V methods volume, speed and assortment), utilizing just basic markers like high (H), medium (M) or low (L).

Applications identified with assessments of harvest creation and yields, land planning, climate anticipating and food security requires enormous volumes of information. Acknowledgment of animals' illnesses and plants' helpless nourishment require high speed, just as choices on ranchers' usefulness, climate gauging and security/nature of food, which should be taken in (close) ongoing.

In these cases, the time skyline of the choices included requires operational or strategic arranging, rather than longer term key arranging (for example lower speed).

All in all, large information investigation in keen cultivating is still at an early improvement stage, and this can be derived from the right now predetermined number of logical distributions and business drives. This reality is upheld by the discoveries recorded in Fig. 1, advanced by Web of Science (Thomson Reuters, 2017). In view of the examination e.g are Big Data, Agriculture and Farm. The plentiful reference index on enormous information, its subset on farming seems, by all accounts, to be generally later and restricted. Notwithstanding, the discoveries show a rising pattern.
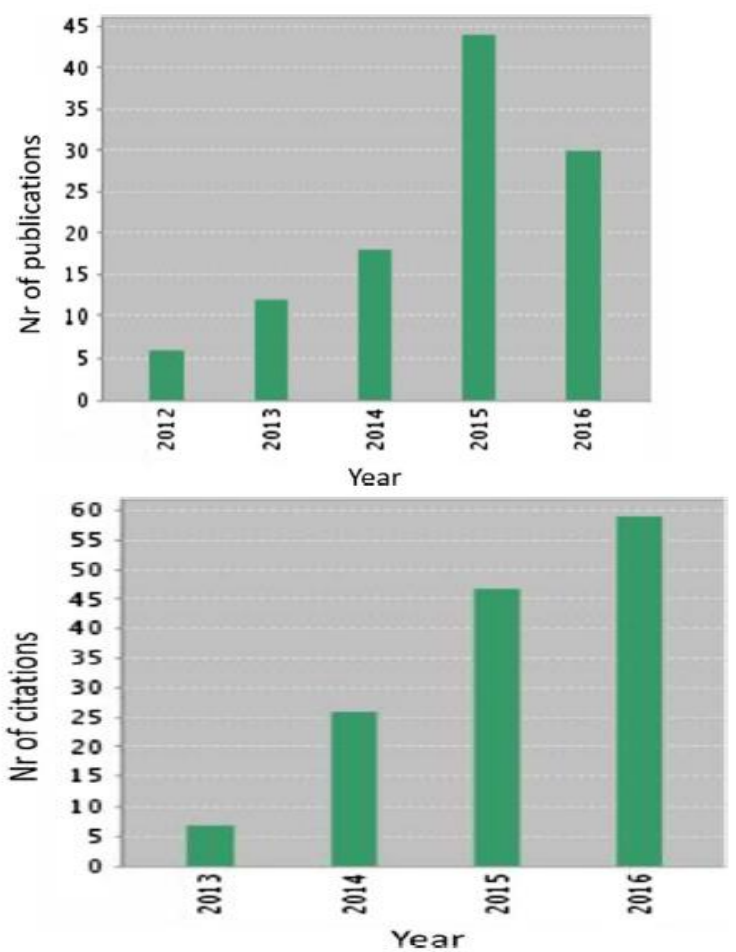
International Journal of Engineering Applied Sciences and Technology, 2021

Vol. 5, Issue 12, ISSN No. 2455-2143, Pages 63-68

Published Online April 2021 in IJEAST (http://www.ijeast.com)

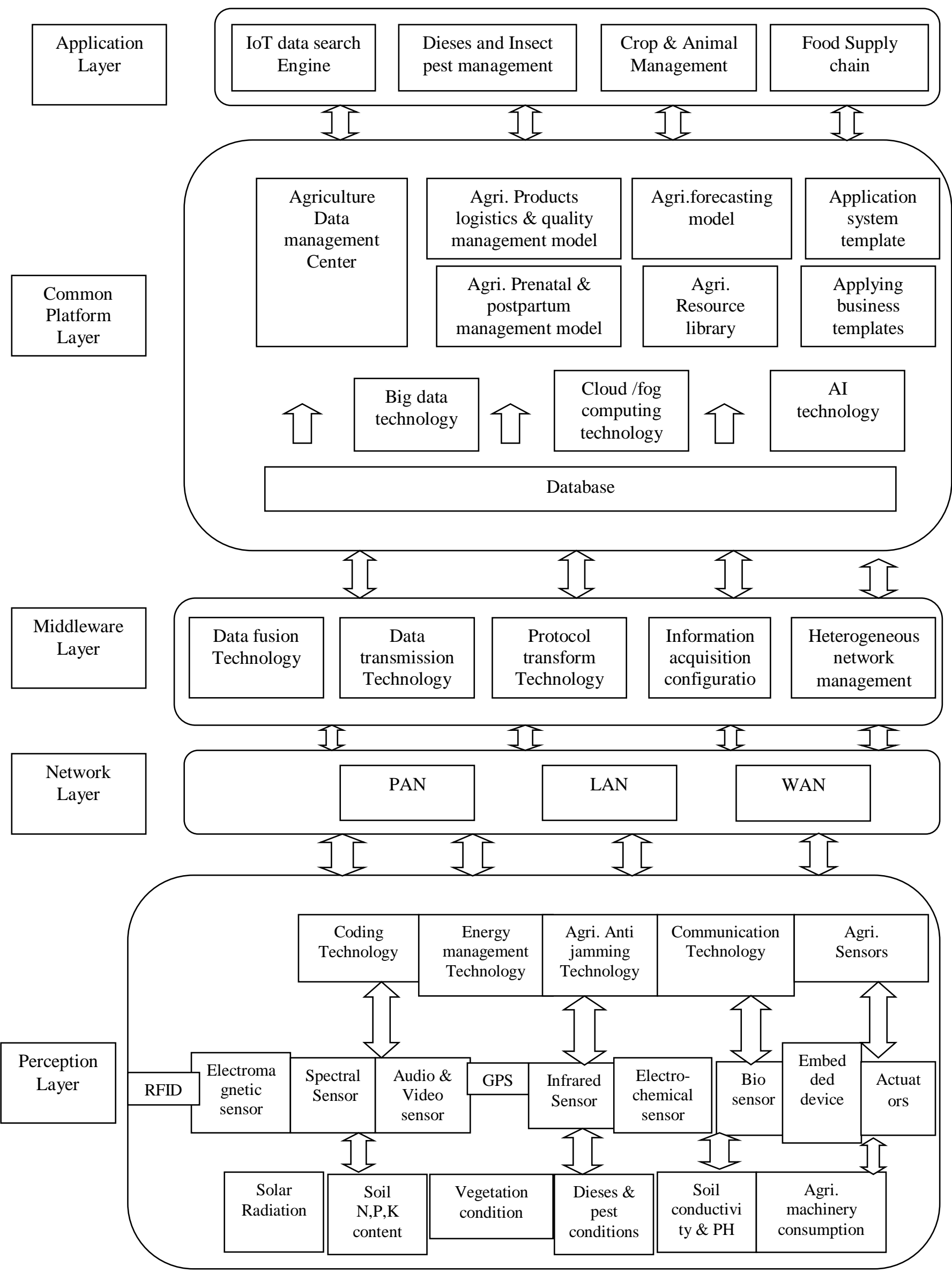




\section{International Journal of Engineering Applied Sciences and Technology, 2021 \\ Vol. 5, Issue 12, ISSN No. 2455-2143, Pages 63-68 \\ Published Online April 2021 in IJEAST (http://www.ijeast.com)}

\section{CONCLUSION}

Thorough audit of the cutting edge in Internet of things sending for secured horticulture applications is portrayed in this survey. Initial, a basic survey of past IoT structure was given. Besides, the essential IoT structures in ensured agribusiness were presented. Next part portrays the sensor, information correspondence, AI, distributed computing, edge registering and other imperative Internet of straps advances in ensured agribusiness are expounded. In this paper, we likewise feature different IoT applications and their benefits to take care of different cultivating issues in ensured farming. Difficulties referenced above should deal with and the future possibilities of Internet of things in ensured farming are eager. To adapt to its intricate and changing rural climate, the equipment gadgets should be completely moved up to additional upgrade their comprehensiveness, dependability, expansibility, perseverance and insight level, while diminishing expenses and usable trouble.

The nearby organization should be shielded from impedance from different organizations is likewise talked about. In specific degree, utilizing different gadgets of Internet of things the interoperability, sifting and semantic comment of information created is likewise figured it out. By utilizing a lot of heterogeneous information we upgrade the Big Data choice help model. We likewise embraced frameworks like security, namelessness and authority over the entrance rights on the data. At last, the effect of Internet of things on the agro natural climate and social economy ought to be considered in the use of secured horticulture, to understand the supportable advancement of farming climate as fast as could really be expected. As we found in this study, there is accessibility and transparency of equipment and programming methods. There will be expanding accessibility of huge information sources and datasets support more drives and new businesses in the agrarian area projects.

\section{REFERENCE}

[1] Lee, M., Hwang, J., \& Yoe, H."Agricultural Production System Based on IoT"Computational Science and Engineering (CSE), 2013 IEEE 16th International Conference on (pp. 833-837).

[2] Patil, V. C., Al-Gaadi, K. A., Biradar, D. P., \& Rangaswamy, M. "Internet of things (Iot) and cloud computing for agriculture: An overview".Proceedings of Agro-Informatics and Precision Agriculture (AIPA 2012), India, 292-296.

[3] Nayyar, A. "An Encyclopedia Coverage of Compiler's, Programmer's \& Simulator's for 8051, PIC, AVR, ARM, Arduino Embedded Technologies". International Journal of Reconfigurable and Embedded Systems (IJRES2013),5(1).

[4] Nayyar, A., \& Puri, V. Data Glove "Internet of Things (IoT) Based Smart Wearable Gadget”. British Journal of Mathematics \& Computer Science, (2016). 15(5).
[5] Bell, J., Butler, C., Thompson, J. "Soil-terrain modeling for site-specific agricultural management. Site-Specific Management for Agricultural Systems", American Society of Agronomy, Crop Science Society of America, Soil Science Society of America, ., 1995 pp. 209-227.

[6] Karmas, A., Karantzalos, K., Athanasiou, S. "Online analysis of remote sensing data for agricultural applications" OSGeo's European conference on free and open source software for geospatial., 2014.

[7]. Karmas, A., Tzotsos, A. \& Karantzalos, K.," Geospatial Big Data for Environmental and Agricultural Applications". In: s.l.: Springer International Publishing, pp. 353-390. Kempenaar, C., AgGateway, 2005. [Online] Available at:http://www.aggateway.org/Home.aspx (accessed 2017).

[8]. Akinboro, B., 2016. "Bringing Mobile Wallets to Nigerian Farmers" [Online] Available at: <http://www.cgap.org/blog/bringing-mobile-walletsnigerian-farmers (accessed 2017).

[9] Yang, X.; Liu, F. "Application of Wireless Sensor Network in Water Quality Monitoring" In Proceedings of the IEEE CSE and EUC Conference, Guangzhou, China, 21-24 July 2017.

[10]. Segun, O.O.; Joubert, T. "Energy Efficient Solutions in Wirelss Sensor Systems for Water Quality Monitoring: A review”. IEEE Sens. J. 2019, 19, 1596-1625.

[11] Pule, M.; Yahya, A.; Chuma, J. "Wireless Sensor Network: A survey on monitoring water quality" J. Appl. Res. Technol. 2017, 15, 562-570.

[12] Chen, Y.; Han, D.”Water Quality Monitoring in Smart City: A pilot project". J. Autom. Constr. 2018, 89, 307-316.

[13]. Bandur, D.; Jaksic, B.; Bandur, M.; Jovic, S." An Analysis of Energy Efficiency in Wireless Sensor Network (WSNs) applied in smart agriculture" Comput. Electron. Agric. 2019, 156, 500-507.

[14] Muangprathuba, J.; Boonnama, B.; Kajornkasirat, S.; Lekbangpong, N.;Wanichsombat, A.; Nillaor, P." IoT and agriculture data analysis for smart farm" Comput. Electron. Agric. 2019, 156, 467-474.

[15] Goap, A.; Sharma, D.; Shukla, A. Krishna, C. "An IoT based smart irrigation management system using Machine learning and open source technologies" Comput. Electron. Agric. 2018, 155, 41-49.

[16] Munir, M.S.; Bajwa, I.S.; Naeem, M.A.; Ramzan, B. "Design and Implementation of an IoT System for Smart Energy Consumption and Smart Irrigation in Tunnel Farming”. Energies 2018, 11, 3427. 